\title{
Proceedings of the Fourth Asian Meeting on Electroceramics (AMEC-4), Hangzhou, China, June 27-30, 2005
}

\author{
Guest Editors
}

Xi Yao

Functional Materials Research Laboratory, Tongji University, Shanghai, 200092, China

\section{Xiang Ming Chen}

Department of Materials Science and Engineering, Zhejiang University, Hangzhou, 310027, China

\section{Ce Wen Nan}

Department of Materials Science and Engineering, Tsinghua University, Beijing, 100084, China

\section{Foreword}

The fourth Asian Meeting on Electroceramics (AMEC-4) was held in Hangzhou, China, June 27-30, 2005. The objective of this meeting is to continue the great initiative and momentum of AMEC-1 (2000, Japan), AMEC-2 (2002, Japan) and AMEC-3 (2003, Singapore), strengthen R \& D activities on electroceramics in Asia and in the world, bridge academic scholars with industrial researchers, and promote AMEC as an international forum in this increasingly important area.

The topics of this conference included almost all areas of electroceramics including microwave dielectrics, tunable ceramics and devices, thin and thick films, ferroelectrics, pyroelectrics, piezoelectrics, magnetic ceramics, conductive ceramics, optic ceramics, ceramic sensors, physics and chemistry of electroceramics, structure and property measurement and characterization, etc.

The conference attracted 367 delegates from 22 countries and regions around the world including China, Japan, Korea, the United States, Europe and Australia. During the 3-day meeting, 63 invited and 142 contributed papers were presented orally and 215 as posters. Professor L.E. Cross and Professor X. Yao gave their keynote lectures at the beginning of the conference. The conference received 252 manuscripts from the delegates, and 204 of them were finally accepted for publication in this special issue after peer-review process following the academic standard of the Journal. However, considering many of the authors are nonEnglish native speaker, our demand on wording is generously moderate, as long as the paper is readable and understandable.

We would like to express our sincere thanks to the editorial board of the Journal and the publisher for their generous support of publishing this proceeding. Acknowledgements are due to Professors J.M. Liu, H. Wang, and J.W. Zhai, and Dr. X.Q. Liu for their special effort and help in the reviewing and editing process. 